\title{
Relationship between the DTA peak and the phase diagram: symbiosis between a thermodynamic database and a DTA curve
}

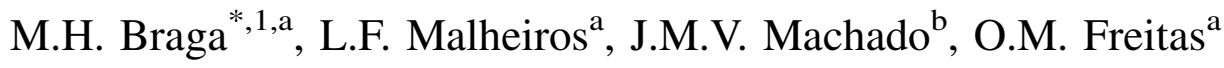 \\ ${ }^{\mathrm{a}}$ GMM/IMAT, Dep. Eng Metalúrgica, Faculdade de Engenharia UP, Porto, Portugal \\ ${ }^{\mathrm{b}}$ Dep. Eng Química, Faculdade de Engenharia UP, Porto, Portugal
}

\begin{abstract}
The shape of a differential thermal analysis (DTA) curve depends on the sample and the reference, the heating or cooling rates used in the experiment as also the thermal resistance to heat flow from the heat source to the cell containing the sample (or the reference), $R_{\mathrm{a}}\left(R_{\mathrm{r}}\right)$. Having access to a database that contains the values of the sample heat capacity, $C_{\mathrm{p}}$, and those of the enthalpy of transformation, $H$, and calculating the parameters that depend on the apparatus, the cells and the reference, as well as the heating rate used, it is possible to determine the $\Delta T\left(T_{\mathrm{a}}-T_{\mathrm{r}}\right)$ values through the equation

$T_{\mathrm{a}}-T_{\mathrm{r}}=R_{\mathrm{a}} \frac{\mathrm{d} H}{\mathrm{~d} t}+R_{\mathrm{r}} C_{\mathrm{r}} \frac{\mathrm{d} T_{\mathrm{r}}}{\mathrm{d} t}-R_{\mathrm{a}} C_{\mathrm{a}} \frac{\mathrm{d} T_{\mathrm{a}}}{\mathrm{d} t}$

where $C_{\mathrm{a}}$ is the heat capacity of the cell + sample system and $C_{\mathrm{b}}$ the heat capacity of the cell + reference system. The comparison between the calculated and experimental values for $\Delta T$ enables an assessment to be made as to whether the modelled parameters are in agreement with the experimental information. This procedure enables a deeper perception of the thermal analysis in general and of the apparatus used in particular. (C) 1999 Elsevier Science S.A. All rights reserved.
\end{abstract}

Keywords: Differential thermal analysis (DTA); Phase diagram's modelling

\section{Introduction}

Phase diagrams contain condensed data about the physic state of materials. Such information is introduced into a database following the thermodynamic modelling of the system, developed essentially from experimental data [1].

Differential thermal analysis (DTA) is a technique based on the temperature difference between a reference cell and another that contains the sample, for a constant heating or cooling rate [2]. The solidus and liquidus temperatures are determined from the DTA curves from the 'key values' associated with the commonly-named endothermic and exothermic peaks. Furthermore, the configuration of the DTA curve also gives some information about the sample, the reference, the type of cells, the heating and cooling rates

*Corresponding author. Tel: +351-2-204-1790; fax: +351-2-204-1792

E-mail address: mbraga@fe.up.pt (M.H. Braga)

${ }^{1}$ PRAXIS XXI's grant holder. as well as the heat flow from the heat source to the cell containing the sample.

\section{Experimental work}

The $\mathrm{Cu}-\mathrm{Zr}$ system, which has already been modelled by the authors [3], was chosen for the study of the relationship between the peaks, the configuration of the DTA curve and the phase diagram. Thus, there was already a database of the equation corresponding to the variation in Gibbs energy with the temperature and composition [3].

The authors used a SETARAM TGDTA92 apparatus, which enables operation within the 293-1873 K temperature range. All the experiments were conducted under an argon atmosphere, at a constant pressure of $1.12 \times 10^{5} \mathrm{~Pa}$. The cells were pure alumina, of $100 \mu \mathrm{l}$ capacity, also supplied by SETARAM. One of the cells contained the sample to be tested, and in the other, no sample was introduced. Thus, as the cells were fully open, the reference used corresponds to the sample volume in argon. 
Right at the beginning, the authors conducted some experiments with standard samples of pure $\mathrm{In}, \mathrm{Al}$ and $\mathrm{Ni}$ for the same experimental conditions as the ones to be used for the $\mathrm{Cu}-\mathrm{Zr}$ system. The heating rate was $5^{\circ} \mathrm{C} / \mathrm{min}$. Just before each experiment with the samples, a 'baseline' was obtained for the empty cells for the same experimental conditions as the ones to be used for the $\mathrm{Cu}-\mathrm{Zr}$ system. So, it could be affirmed that both cells contain the same reference (argon).

\section{Results and discussion}

In DTA, the heat balance in the cells containing the sample and the reference can be defined by the expressions [4]

$\frac{\mathrm{d} Q_{\mathrm{a}}}{\mathrm{d} t}=C_{\mathrm{a}} \frac{\mathrm{d} T_{\mathrm{a}}}{\mathrm{d} t}-\frac{\mathrm{d} H}{\mathrm{~d} t} ; \quad \frac{\mathrm{d} Q_{\mathrm{r}}}{\mathrm{d} t}=C_{\mathrm{r}} \frac{\mathrm{d} T_{\mathrm{r}}}{\mathrm{d} t}$

where $C_{\mathrm{a}}\left(C_{\mathrm{r}}\right)$ is the heat capacity of the cell + sample (reference) system, $Q_{\mathrm{a}}\left(Q_{\mathrm{r}}\right)$ the heat supplied to the sample (reference), $T_{\mathrm{a}}\left(T_{\mathrm{r}}\right)$ the temperature of the cell containing the sample (reference), $H$ the enthalpy of transformation and $t$ the time.

By Newton's law [2]

$$
\begin{gathered}
C_{\mathrm{a}} \frac{\mathrm{d} T_{\mathrm{a}}}{\mathrm{d} t}=\frac{\left(T_{\mathrm{f}}-T_{\mathrm{a}}\right)}{R_{\mathrm{a}}}+\frac{\mathrm{d} H}{\mathrm{~d} t} ; \quad C_{\mathrm{r}} \frac{\mathrm{d} T_{\mathrm{r}}}{\mathrm{d} t}=\frac{\left(T_{\mathrm{f}}-T_{\mathrm{r}}\right)}{R_{\mathrm{r}}} \\
\Downarrow \\
T_{\mathrm{a}}-T_{\mathrm{r}}=R_{\mathrm{a}} \frac{\mathrm{d} H}{\mathrm{~d} t}+R_{\mathrm{r}} C_{\mathrm{r}} \frac{\mathrm{d} T_{\mathrm{r}}}{\mathrm{d} t}-R_{\mathrm{a}} C_{\mathrm{a}} \frac{\mathrm{d} T_{\mathrm{a}}}{\mathrm{d} t}
\end{gathered}
$$

where $T_{\mathrm{f}}$ is the temperature of the heat source and $R_{\mathrm{a}}\left(R_{\mathrm{r}}\right)$ the thermal resistance to heat flow from the heat source to the cell containing the sample (reference).

By tracing the baseline for cells that do not contain a sample, any transformation in the temperature range of the experiment $(\mathrm{d} H / \mathrm{d} t=0)$ will not occur:

$\left(T_{\mathrm{a}}-T_{\mathrm{r}}\right)_{\mathrm{b} .1 .}=R_{\mathrm{r}}\left(C_{\mathrm{r}}^{\prime}+C_{\mathrm{r}}^{\prime \prime}\right) \frac{\mathrm{d} T_{\mathrm{r}}}{\mathrm{d} t}-R_{\mathrm{a}}\left(C_{\mathrm{a}}^{\prime}+C_{\mathrm{a}}^{\prime \prime}\right) \frac{\mathrm{d} T_{\mathrm{a}}}{\mathrm{d} t}$

where $C_{\mathrm{r}}^{\prime}=C_{\mathrm{a}}^{\prime}$ is the heat capacity per unit volume of the reference cell (equal to that containing the sample) and $C_{\mathrm{r}}^{\prime \prime}\left(C_{\mathrm{a}}^{\prime \prime}\right)$ the heat capacity per unit volume of the reference (sample).

As (i) the cells are hypothetically equal and (ii) the sample and the reference are the same (argon used as flushing gas)

$\left(T_{\mathrm{a}}-T_{\mathrm{r}}\right)_{\mathrm{b} .1 .}=R_{\mathrm{r}}-R_{\mathrm{a}}\left(C_{\mathrm{r}}^{\prime}+C_{\mathrm{r}}^{\prime \prime}\right) \frac{\mathrm{d} T_{\mathrm{r}}}{\mathrm{d} t}$

It should be emphasized that, in the last two expressions, it has been considered that the heat capacity per unit volume as a comparison is established between the sample and the corresponding volume of argon. For an experiment with a standard sample and deducting the baseline effect

$$
\begin{aligned}
& \left(T_{\mathrm{a}}-T_{\mathrm{r}}\right)-\left(T_{\mathrm{a}}-T_{\mathrm{r}}\right)_{\mathrm{b} .1 .} \\
& \quad=R_{\mathrm{a}} \frac{\mathrm{d} H}{\mathrm{~d} t}+R_{\mathrm{a}}\left(C_{\mathrm{r}}^{\prime}+C_{\mathrm{r}}^{\prime \prime}\right) \frac{\mathrm{d} T_{\mathrm{r}}}{\mathrm{d} t}-R_{\mathrm{a}}\left(C_{\mathrm{r}}^{\prime}+C_{\mathrm{a}}^{\prime \prime}\right) \frac{\mathrm{d} T_{\mathrm{a}}}{\mathrm{d} t}
\end{aligned}
$$

If $\alpha=\mathrm{d} T_{\mathrm{a}} / \mathrm{d} t=\mathrm{d} T_{\mathrm{r}} / \mathrm{d} t, \alpha$ being the heating rate, and as just before and after any transformation, $\mathrm{d} H / \mathrm{d} t=0$

$$
\begin{gathered}
\left(T_{\mathrm{a}}-T_{\mathrm{r}}\right)-\left(T_{\mathrm{a}}-T_{\mathrm{r}}\right)_{\mathrm{b} .1 .}=R_{\mathrm{a}}\left(C_{\mathrm{r}}^{\prime \prime}-C_{\mathrm{a}}^{\prime \prime}\right) \alpha \\
\Downarrow \\
R_{\mathrm{a}}=\frac{\left(T_{\mathrm{a}}-T_{\mathrm{r}}\right)-\left(T_{\mathrm{a}}-T_{\mathrm{r}}\right)_{\mathrm{b} .1 .}}{\alpha\left(C_{\text {argon }}-C_{\text {standard }}\right)}
\end{gathered}
$$

The resolution of this equation will give the value for the thermal resistance to heat flow from the heat source to the cell containing the sample.

Taking into account the weight of the standard sample, its density [5] and its heat capacity [6] as functions of the temperature, and that argon can be considered an ideal gas (at least for the temperature range and pressure of the experiments), the value for $R_{\mathrm{a}}$ can be determined as a function of the temperature, for the standards already mentioned. For the same temperature, the values obtained for the resistance are quite similar.

Nevertheless, an exception has been registered with the Im test in which, by experimental difficulties associated essentially with the sample oxidation, only a point for comparison at $373 \mathrm{~K}$ has been obtained, a temperature that is quite near to its melting point (429.6 K [7]). The authors have also come to the conclusion that the resistance doesn't vary too much with the temperature, at least in the temperature range of the experiments $(\sim 298-\sim 1473 \mathrm{~K})$. Thus, it seems quite correct to consider a mean value for that resistance (see Table 1) over that temperature range.

Also, the thermal resistance to heat flow from the heat source to the cell containing the sample ( $\mathrm{Ni}$ standard) has been compared to that for alumina [8] (the support of the cells was in pure alumina [9]) in order to establish a qualitative comparison. The results are presented graphically in Fig. 1.

It should be noted that the DTA curve for the Ni standard sample could be affected, and consequently, the calculation of the value for $R_{\mathrm{a}}$, by the second-order transformation (ferromagnet $\rightarrow$ paramagnet) observed for $\mathrm{Ni}$ at $633 \mathrm{~K}$ [7].

The oxidation of $\mathrm{Ni}$, perfectly identified from $\sim 850 \mathrm{~K}$ in the graph representing the variation in the weight of the sample with the temperature (see Fig. 1), has probably

Table 1

Mean values for the thermal resistance to heat flow from the heat source to the cell containing the sample

\begin{tabular}{ll}
\hline Standard sample & $R_{\text {mean }}\left(\times 10^{7}\right)\left(\mathrm{Km}^{3} \mathrm{~s} / \mathrm{J}\right)$ \\
\hline $\mathrm{In}$ & 0.9 \\
$\mathrm{Al}$ & 3.3 \\
$\mathrm{Ni}$ & 3.3 \\
\hline
\end{tabular}




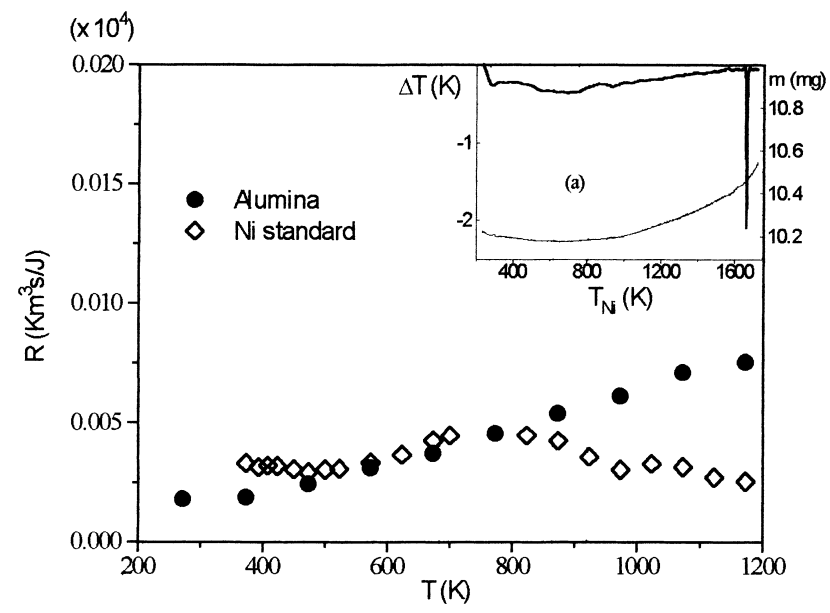

Fig. 1. Comparison between the thermal resistance to heat flow from the heat source to the cell containing the sample (Ni standard) and that for alumina. (a) DTA curve for the Ni standard sample.

affected the DTA curve, and in consequence, the calculation of the thermal resistance.

After having determined the values of $R_{\mathrm{a}}$ for the different standards, some DTA experiments have been conducted with samples of the $\mathrm{Cu}-\mathrm{Zr}$ system for $x(\mathrm{Zr})=0.536$, the equilibria of which for $T=1184.8 \mathrm{~K}$ and $T=1187.8 \mathrm{~K}$ [3], respectively, are already known as

$\mathrm{fcc}-\mathrm{A} 1+\mathrm{Cu}_{5} \mathrm{Zr}_{8} \leftrightarrow \mathrm{CuZr}+\mathrm{Cu}_{5} \mathrm{Zr}_{8}$

and

fcc-A $1 \leftrightarrow$ fcc-A $1+\mathrm{Cu}_{5} \mathrm{Zr}_{8}$

This alloy has been chosen in order to test the symbiosis between the values from a database and the experimental data obtained from a DTA curve. Thus, the curve obtained by DTA experiments for the selected alloy of the $\mathrm{Cu}-\mathrm{Zr}$ system has been compared to the curve drawn from the

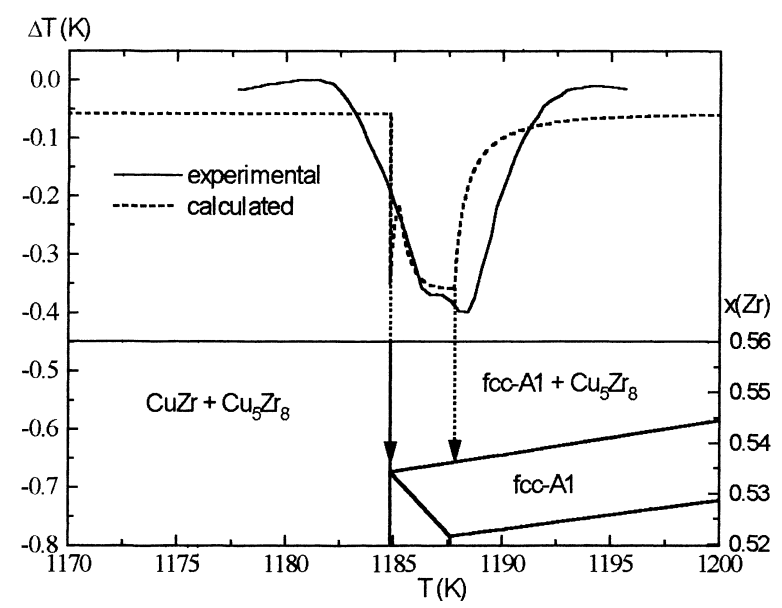

Fig. 2. Comparison between the DTA curves obtained from experimental data and by calculation from the database. Superimposition with the phase diagram where the different reactions corresponding to the selected alloy of the $\mathrm{Cu}-\mathrm{Zr}$ system are represented. values for the heat capacity and the enthalpy of transformation taken from a database [1,3] (see Fig. 2). For the first reaction (eutectoid), ideally isothermal, we have for the onset

$\left(T_{\mathrm{a} 0}-T_{\mathrm{r} 0}\right)-\left(T_{\mathrm{a}}-T_{\mathrm{r}}\right)_{\mathrm{b} .1 .}=R_{\mathrm{a}}\left(C_{\mathrm{r}}^{\prime \prime}-C_{\mathrm{a}}^{\prime \prime}\right) \frac{\mathrm{d} T_{\mathrm{r}}}{\mathrm{d} t}$

in which $T_{\mathrm{a} 0}$ represents the temperature for the equilibrium in accordance with the diagram already modelled [3] (see Fig. 2). Thus, taking into account that, for an isothermal reaction, $\mathrm{d} H / \mathrm{d} t=0$,

$$
\begin{gathered}
\left(T_{\mathrm{a}}-T_{\mathrm{r}}\right)-\left(T_{\mathrm{a}}-T_{\mathrm{r}}\right)_{\mathrm{b} .1 .}=\left[T_{\mathrm{a} 0}-\left(T_{\mathrm{r} 0}+\frac{\mathrm{d} T_{\mathrm{r}}}{\mathrm{d} t} t\right)\right] \\
-\left(T_{\mathrm{a}}-T_{\mathrm{r}}\right)_{\mathrm{b} .1 .}=R_{\mathrm{a}}\left(C_{\mathrm{r}}^{\prime \prime}-C_{\mathrm{a}}^{\prime \prime}\right) \frac{\mathrm{d} T_{\mathrm{r}}}{\mathrm{d} t}-\frac{\mathrm{d} T_{\mathrm{r}}}{\mathrm{d} t} t
\end{gathered}
$$

Just after the reaction, $\mathrm{d} H / \mathrm{d} t$ is still null, and in consequence (see Eq. (6)),

$$
\begin{aligned}
& \left(T_{\mathrm{a}}-T_{\mathrm{r}}\right)-\left(T_{\mathrm{a}}-T_{\mathrm{r}}\right)_{\mathrm{b} . \mathrm{l} .} \\
& \quad=R_{\mathrm{a}}\left(C_{\mathrm{r}}^{\prime}+C_{\mathrm{r}}^{\prime \prime}\right) \frac{\mathrm{d} T_{\mathrm{r}}}{\mathrm{d} t}+R_{\mathrm{a}}\left(C_{\mathrm{r}}^{\prime}+C_{\mathrm{a}}^{\prime \prime}\right) \frac{\mathrm{d} T_{\mathrm{a}}}{\mathrm{d} t}
\end{aligned}
$$

This equation has been solved by Laplace's transforms [10] in order to analyse its resolution as a function of the different parameters:

$$
\begin{aligned}
T_{\mathrm{a}}= & T_{\mathrm{a} 0} \exp \left(-\frac{t}{R_{\mathrm{a}}\left(C_{\mathrm{r}}^{\prime}+C_{\mathrm{a}}^{\prime \prime}\right)}\right) \\
& +\left[T_{\mathrm{r} 0}+\Delta T_{\mathrm{b} .1 .}+R_{\mathrm{a}} \alpha\left(C_{\mathrm{r}}^{\prime \prime}-C_{\mathrm{a}}^{\prime \prime}\right)\right] \\
& \times\left(1-\exp \left(-\frac{t}{R_{\mathrm{a}}\left(C_{\mathrm{r}}^{\prime}+C_{\mathrm{a}}^{\prime \prime}\right)}\right)\right)+\alpha t \\
& \Downarrow \\
\left(T_{\mathrm{a}}-\right. & \left.T_{\mathrm{r}}\right)-\Delta T_{\mathrm{b} .1 .}=\left(\Delta T_{\max }-\Delta T_{\mathrm{b} .1 .}\right) \exp \left(-\frac{t}{R_{\mathrm{a}}\left(C_{\mathrm{r}}^{\prime}+C_{\mathrm{a}}^{\prime \prime}\right)}\right) \\
+ & {\left[R_{\mathrm{a}} \alpha\left(C_{\mathrm{r}}^{\prime \prime}-C_{\mathrm{a}}^{\prime \prime}\right)\right]\left(1-\exp \left(-\frac{t}{R_{\mathrm{a}}\left(C_{\mathrm{r}}^{\prime}+C_{\mathrm{a}}^{\prime \prime}\right)}\right)\right) }
\end{aligned}
$$

where $T_{\mathrm{r}}=T_{\mathrm{r} 0}+\alpha t, C_{\mathrm{r}}^{\prime}$ is the heat capacity per unit volume for alumina [8], $C_{\mathrm{r}}^{\prime \prime}$ is the heat capacity per unit volume for $\operatorname{argon}, C_{\mathrm{a}}^{\prime \prime}$ is the heat capacity per unit volume for the alloy of the system $\mathrm{Cu}-\mathrm{Zr}[1,3]$ and $t$ is the time taken from the peak.

It should be emphasized that the expression $T_{\mathrm{a} 0}-$ $T_{\mathrm{r} 0}=\Delta T_{\max }$ is valid from the peak that corresponds to the end of the reaction, and in consequence, is valid for all the systems.

It should also be noted that all the information necessary for the control of the time span $(t)$ for a given calculation, governed by a particular equation (for example, for the eutectoid reaction mentioned earlier, the time span between the reaction onset and the peak) has been taken from the experimental data file.

For the calculations, $R_{\mathrm{a}}$ has been taken as $3.3 \times$ $10^{-7} \mathrm{Km}^{3} \mathrm{~s} / \mathrm{J}$ and equal to the mean value obtained for the thermal resistance in the experiments with the $\mathrm{Al}$ and Ni standard samples (see Table 1). 
For the second reaction mentioned earlier for the alloy of the $\mathrm{Cu}-\mathrm{Zr}$ system selected (for which $\mathrm{d} H / \mathrm{d} t \neq 0$ ), the calculation of $\left(T_{\mathrm{a}}-T_{\mathrm{r}}\right)$ has been developed from Eq. (6) by the application of the Butcher method [11], using a specific routine created in Fortran 77. In this case, the resolution of Eq. (6) by the application of Laplace's transforms is not possible as the variation in the heat capacity of the sample with the temperature during the reaction should have been taken into account. Thus, the specific routine developed by the present authors has been used, bearing in mind that $\mathrm{d} H$ / $\mathrm{d} t\left(T_{\mathrm{a}}(t)\right), C_{\mathrm{r}}=C_{\mathrm{r}}\left(T_{\mathrm{r}}\right)$ and $C_{\mathrm{a}}=C_{\mathrm{a}}\left(T_{\mathrm{a}}\right) \cdot \mathrm{d} H / \mathrm{d} t\left(T_{\mathrm{a}}(t)\right)$ and the heat capacity per unit volume $C_{\mathrm{a}}^{\prime \prime}=C_{\mathrm{a}}^{\prime \prime}\left(T_{\mathrm{a}}\right)$ have been calculated from the database's content $[1,3]$ (data concerning the thermodynamic functions and the phase diagrams).

It should be noted that all the calculations have taken into account the expansion of the sample with temperature because it affects not only the properties of the sample itself but also the properties of the reference. Effectively, during the experiments, the volume of the reference has always been taken as equal to the volume of the sample tested. Nevertheless, it is observed that such a correction does not influence the final results too much.

\section{Conclusions}

From the calculation of the thermal resistance $\left(R_{\mathrm{a}}\right)$ to heat flow from the heat source to the cell containing the sample, and from the baseline and the DTA curve for standard samples, a mean value has been obtained that can be used for other calculations within the temperature range of the experiments $(\sim 298-\sim 1473 \mathrm{~K})$. This value is dependent on the apparatus used, but for the present equipment, is quite independent of the temperature.

The authors have also come to the conclusion, from the calculation of the theoretical curve from the $R_{\mathrm{a}}$ value and the parameters included in the database, that the deviation between the experimental and the calculated results, observed in the eutectoid reaction for the sample of the $\mathrm{Cu}-\mathrm{Zr}$ system, could result from the consideration of an infinite thermal conductance between the sample and its cell (the ideal case [12]). Nevertheless, due to the superficial oxidation always detectable at such high temperatures and that restrains the thermal contact between the sample and its cell, a different value should be considered for the thermal conductance. However, as this parameter is very hard to determine and varies from experiment to experiment, it has been neglected, although its influence is clearly present in the experimental curve. Finally, it can be concluded that the parameters of the database are quite similar to those deduced from the experimental results. The difference $(\sim 2 \mathrm{~K})$ between the calculated and the experimental values for the first onset enables the foreseeing of a small adjustment of the theoretical parameters. On the other hand, the difference between the temperatures for the onset and for the second peak $(5 \mathrm{~K}$ in the experimental curve and $3 \mathrm{~K}$ for the theoretical curve) implies a higher slope for the liquidus curve if the error associated with the atomic fraction of zirconium in the sample of the $\mathrm{Cu}-\mathrm{Zr}$ system chosen is less than $0.3 \%$, which has been totally impossible for the authors to confirm.

The authors are quite sure that they have proven that symbiosis could be established between a database and a DTA curve. By a calculation with the parameters contained in the database, a rough approach to the system can be obtained, concerning essentially the peaks and the respective temperatures. The DTA curve will allow the adjustment, step by step, of those parameters. On the other hand, the calculation of the thermal conductance allows one to know the apparatus better, and in consequence, the DTA curves.

\section{Acknowledgements}

The authors are deeply grateful to Prof. Fonseca Almeida for the loan of the DTA equipment.

\section{References}

[1] M.H. Braga, F. Castro, L.F. Malheiros, Aveiro, Portugal, 18-20 September 1995, in: Proc. Materiais'95, vol. 1, 1995, p. 368.

[2] M.E. Brown, Introduction to Thermal Analysis, Chapman \& Hall, London, 1988.

[3] M.H. Braga, A.I. Ansara, L.F. Malheiros, World Congress Calphad XXV, Erice, Sicilia, 26-31 May, 1996.

[4] S.W. Chen, C.C. Huang, J.C. Lin, Chem. Eng. Sci. 50(3) (1995) 417.

[5] C.J. Smithells, Metals Reference Book, vol. II, Butterworths, London, 1995.

[6] R. Hultgren, R. Orr, P. Anderson, K. Kelley, Selected Values of Thermodynamic Properties of Metals and Alloys, Wiley, New York, 1963.

[7] A.T. Dinsdale, World Congress Calphad 15(4) (1991) 317.

[8] E. Dörre, H. Hübner, Alumina Processing, Properties, and Applications, Springer, New York, 1984.

[9] SETARAM, SETARAM TGDTA92's Manual.

[10] D.E. Seborg, T.F. Edgar, D.A. Mellichamp, Process Dynamics and Control, Wiley Series in Chemical Engineering, Wiley, New York, 1989.

[11] L. Lapidus, J.H. Seinfeld, Numerical Solution of Ordinary Differential Equations, Academic Press, New York, 1971.

[12] R.D. Shull, A. Joshi, Thermal Analysis in Metallurgy, A Publication of TMS Minerals, Metals, Materials, 1992, Pennsylvania, USA. 